05,13

\title{
Корреляция электрических, гальваномагнитных и магнитных характеристик нанокристаллических пленок железа, полученных методом ионно-ассистированного осаждения
}

\author{
(С) В.И. Головчук ${ }^{1}$, Ю.А. Бумай ${ }^{2}$, М.Г. Лукашевич ${ }^{1}$, Н.М. Лядов ${ }^{3}$, И.А. Файзрахманов ${ }^{3}$, Р.И. Хайбуллин ${ }^{3}$ \\ ${ }^{1}$ Белорусский государственный университет, \\ Минск, Беларусь \\ ${ }^{2}$ Белорусский национальный технический университет, \\ Минск, Беларусь \\ ${ }^{3}$ Казанский физико-технический институт им. Е.К. Завойского ФИЦ Казанский научный центр РАН, \\ Казань, Россия \\ E-mail: Golovchuk@bsu.by
}

Поступила в Редакцию 6 июля 2021 г.

В окончательной редакции 6 июля 2021 г.

Принята к публикации 7 июля 2021 г.

\begin{abstract}
Представлены результаты измерений температурной зависимости сопротивления, поперечного и продольного магнитосопротивления (МC) в нанокристаллических пленках железа в температурном интервале $2-300 \mathrm{~K}$ и развертке магнитного поля до 8 Т. Тонкие пленки нанокристаллической $\alpha$-фазы железа толщиной $80 \mathrm{~nm}$ были получены методом ионно-стимулированного осаждения на кремневую подложку. Помимо анизотропии формы, полученные пленки проявляли перпендикулярную магнитную анизотропию (ПМА), которая исчезала после отжига пленок при температуре $450^{\circ} \mathrm{C}$ в условиях вакуума. Экспериментально показано влияние ПМА на знак, величину и магнитополевую зависимость магниторезистивного эффекта, регистрируемого при различной ориентации внешнего магнитного поля по отношению к плоскости пленки и направлению протекания тока. Полученные результаты обсуждаются в рамках современных представлений о процессах переноса заряда без магнитного и в магнитном поле в слабо разупорядоченных ферромагнитных пленках с различной магнитной анизотропией и доменной структурой при наложении слабого (меньше поля насыщения намагниченности) или сильного (выше поля насыщения) внешнего магнитного поля.
\end{abstract}

Ключевые слова: нанокристаллические пленки железа, перпендикулярная магнитная анизотропия, магниторезистивный эффект, анизотропное магнитосопротивление, магнонное магнитосопротивление, перколяция, слабая локализация.

DOI: $10.21883 /$ FTT.2021.12.51670.163

\section{1. Введение}

Широкое применение в магнитоэлектронике и спинтронике тонких магнитных пленок и многослойных гетероструктур с различным типом магнитного упорядочивания в слоях стимулирует постоянный интерес к поиску корреляции между магнитной микроструктурой объекта исследования и его электрическими, гальваномагнитными или магнитоэлектрическими характеристиками [1]. Размерные характеристики наноструктурированных магнитных систем (например, размер кристаллитов, толщина слоев и другие) могут быть сравнимыми (или даже меньше) с корреляционной длиной магнитного упорядочивания и пространственными характеристиками электронного транспорта, такими как длина свободного пробега, длина прыжка или сбоя фазы волновой функции электрона. Поэтому даже при незначительной вариации структурных параметров наноструктурированной системы можно ожидать существенных изменений ее магнитных и магнитотранспортных свойств. Обычно в наноструктурированных системах спин-зависимые процессы рассеяния или туннелирования носителей заряда (электронов) играют ключевую роль в установлении зависимостей электросопротивления от величины внешнего магнитного поля (т. е. магнитосопротивления, МC). При этом величина МС существенно зависит не только от механизма электронного транспорта, но и от угла между вектором намагниченности и направлением протекания тока. Однако, наряду с классическими эффектами анизотропного магнитосопротивления (АМС) [2] или лоренцевского магнитосопротивления (ЛМС) [3], существенное влияние на МС могут оказывать также процессы рассеяние электронов на доменных стенках или электрон-магнонное взаимодействие (магнонное рассеяние) $[4,5]$. Заметим, что вплоть до настоящего времени нет устоявшихся представлений не только о влиянии типа доменных стенок на транспортные характеристики магнитного материала, но и о вкладе процесса смещения доменных стенок при перемагничивании системы на знак и величину наблюдаемого МС. Все отмеченные выше механизмы рассеяния электронов являются спинзависимыми процессами, могут приводить к различным видам магнитополевой зависимости электросопротивления и определять знак и величину магниторезистивного 
эффекта, и, соответственно, должны учитываться при разработке новых спинтронных устройств на основе наноструктурированных магнитных систем [6].

Целью данной работы являлось нахождение корреляции между электрическими (механизм электронного транспорта), гальваномагнитными (знак, величина и вид магнитополевой зависимости МС) и магнитными (магнитная микроструктура, направление намагниченности) характеристиками тонких пленок железа в зависимости от направления внешних электрического и магнитного полей и геометрии измерений для нахождения оптимальных способов управления гальваномагнитными характеристиками путем целенаправленного изменения механизма электронного транспорта, магнитного состояния пленки и проявления геометрических и размерных эффектов как в гальваномагнитных, так и магнитных характеристиках.

\section{2. Микроструктура и магнитные свойства}

Объектом исследования были тонкие (толщиной $d=80 \mathrm{~nm}$ ) нанокристаллические пленки железа, полученные на кремниевой подложке методом ионностимулированного осаждения. Детальное описание условий получения пленок и результаты исследования их микроструктуры, магнитно-фазового состава и магнитных свойств были представлены ранее в работах $[7,8]$. Полученные пленки железа представляли собой наноструктурированный магнитный материал, состоящий из композиции наноразмерных $(\sim 10 \mathrm{~nm})$ кристаллитов $\alpha$-фазы Fе с большой долей (до $40 \%$ ) включений аморфной фазы железа и разделяющей их ультратонкой (менее $1 \mathrm{~nm})$ оксидной прослойки $\left(\mathrm{Fe}_{1-x} \mathrm{O}\right.$ или $\left.\mathrm{Fe}_{3} \mathrm{O}_{4}\right)$. Было показано, что при определенных режимах ионностимулированного осаждения нанокристаллические (нанокомпозитные по фазам железа) пленки проявляют при комнатной температуре перпендикулярную магнитную анизотропию (ПМА), величина которой определяется скоростью осаждения пленки [8]. Установлено, что природа возникновения ПМА связана с микронапряжениями (магнетоупругим эффектом) в нанокристаллической фазе железа, возникающими в процессе роста пленок за счет наличия в пленке аморфной фазы железа и оксидной прослойки $\left(\mathrm{Fe}_{1-x} \mathrm{O}\right)$. После термического отжига полученных пленок железа при температуре $T=450^{\circ} \mathrm{C}$ в течение $15 \mathrm{~min}$ в условиях вакуума $\left(10^{-2} \mathrm{~Pa}\right)$ средний размер кристаллитов $\alpha$-фазы Fе возрастал до $20-30 \mathrm{~nm}$ за счет кристаллизации аморфной фазы, микронапряжения снимались и ПМА в нанокристаллических пленках железа полностью исчезала $[7,8]$.

В настоящей работе для выявления влияния ПМА на магнитотранспортные свойства нанокристаллических пленок железа мы использовали два типа пленок с различной магнитной анизотропией. А именно, исходноосажденные пленки железа, проявляющие ПМА с по-
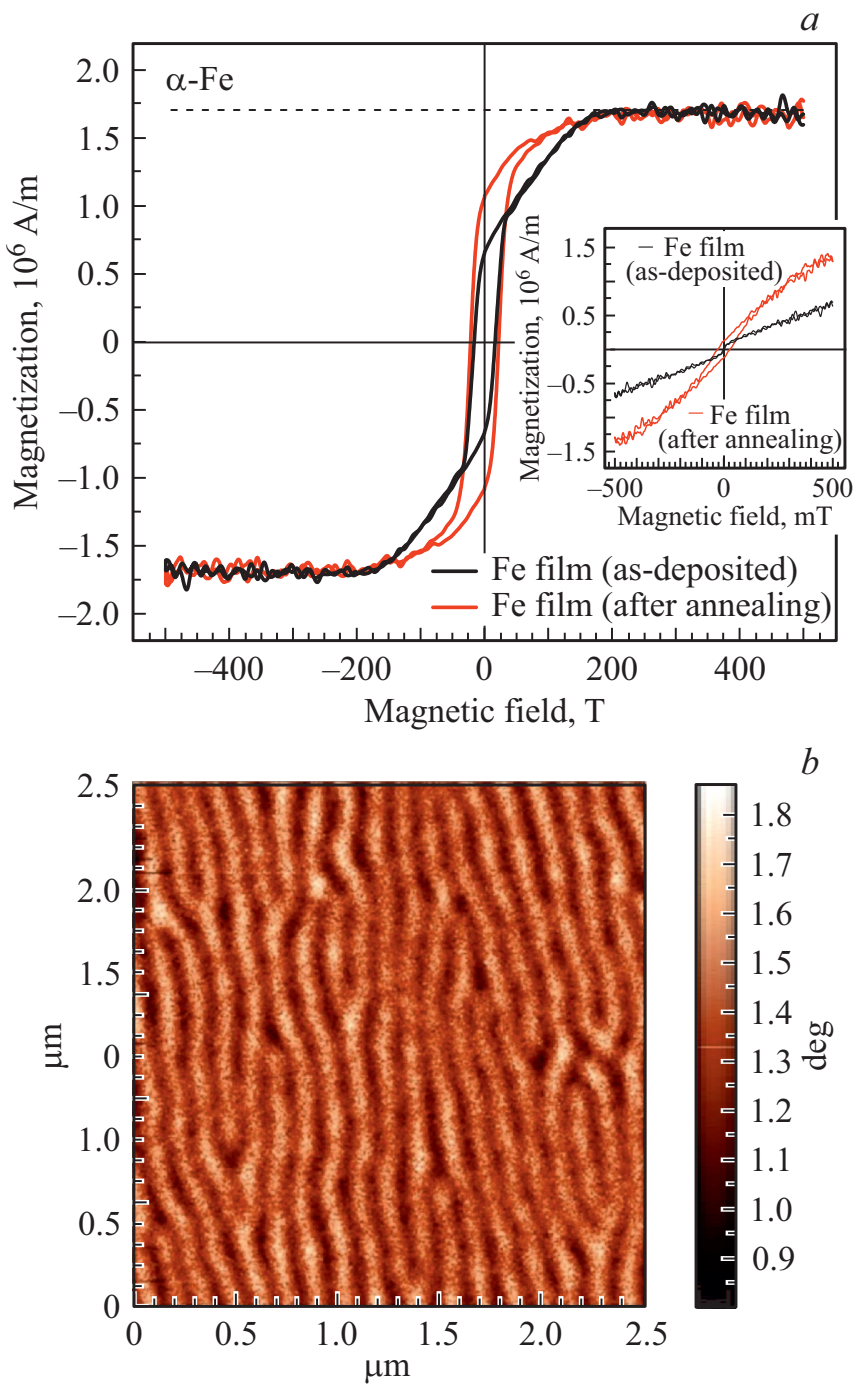

Рис. 1. $a$ ) кривые намагничивания исходно-осажденной (asdeposited) и последовательно отожженной (annealed) пленок железа при комнатной температуре и сканировании магнитного поля в плоскости пленки. На вставке к рисунку представлены кривые намагничивания тех же пленок при сканировании магнитного поля перпендикулярно плоскости пленки; $b$ ) изображение полосовой доменной структуры, полученное с использованием магнитно-силовой сканирующей микроскопии, в исходно-осажденной нанокристаллической пленке железа.

лем анизотропии $B_{a} \cong 180 \mathrm{mT}$, и подобные им пленки, подвергнутые дополнительному термическому отжигу в вакууме, в которых ПМА отсутствовала. О наличии ПМА в исходно-осажденных нанокристаллических пленках железа свидетельствуют транскритическая по форме петля магнитного гистерезиса, регистрируемая при сканировании магнитного поля в плоскости пленки (см. рис. $1, a$, кривая 1 ), а также наблюдение полосовой доменной структуры, представленной на рис. $1, b$, где светлые и темные полосы соответствуют перпендикулярным компонентам намагниченности в домене, 
направленным в противоположные стороны. В отличие от исходно осажденной нанокристаллической пленки железа, отожженный образец той же пленки проявляет петлю магнитного гистерезиса, типичную для поликристаллических пленок железа (рис. 1, $a$, кривая 2). Отметим, что для обоих типов пленок железа (как с ПМА, так и без нее) при регистрации кривых намагничивания вдоль нормали к плоскости пленки (см. вставку к рис. 1,a) доминирующее влияние на процесс намагничивания пленок оказывает анизотропия формы из-за высокого значения спонтанной намагниченности $\alpha$-фазы Fe.

\section{3. Методика измерения электро- и магнетосопротивления}

Омические контакты к наноструктурированном пленкам железа изготавливались путем ультразвуковой пайки медных проволочек. Петли гистерезиса поперечного и продольного МС измерялись на линейном участке вольт-амперной характеристики при сканировании магнитного поля до $8 \mathrm{~T}$ в двух направлениях без предварительного размагничивания образца перед каждым измерением. Измерения проводились в температурном интервале от 2 до $300^{\circ} \mathrm{K}$ при нагревании образцов, предварительно охлажденных в нулевом магнитном поле до температур жидкого гелия. Поперечный магниторезистивный эффект измерялся при двух значениях угла между направлением вектора магнитного поля и плоскостью пленки, а именно: $\varphi=0$ и $\varphi=90^{\circ}$, а продольный - при $\varphi=0^{\circ}$. Для установления доминирующего механизма переноса электронов в разных температурных интервалах были проведены измерения температурных зависимостей электросопротивления. Все измерения проводились в режиме стабилизации тока, протекающего в плоскости железной пленки.

\section{4. Результаты и их обсуждение}

Как отмечалось выше, синтезированные пленки представляют собой наноструктурированный материал, в котором нанокристаллиты $\alpha$-железа с диаметром $\sim 10 \mathrm{~nm}$ разделены неупорядоченными прослойками аморфной и оксидной фаз железа. После отжига размеры кристаллитов увеличиваются до 20-30 nm, а неупорядоченная прослойка практически исчезает. В таких пленках при изменении температуры следует ожидать доминирования разных механизмов электронного транспорта. В области высоких температур наиболее важными могут быть активационный или перколяционный, а в области низких температур - диффузионный, процессы туннелирования или слабой локализации в зависимости от структурного совершенства. Температурные зависимости сопротивления исходной и отожженной пленки показаны на рис. 2, $a$ и $b$.
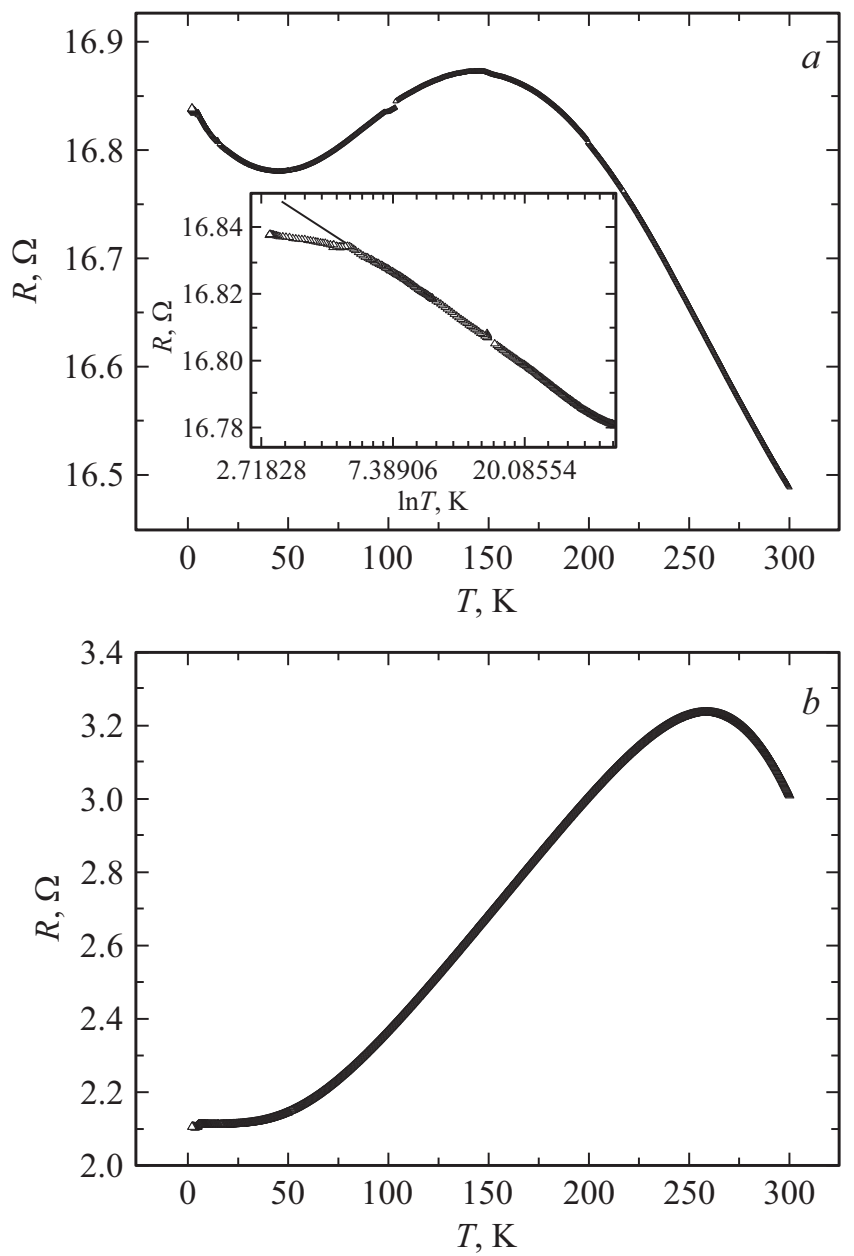

Рис. 2. Температурная зависимость сопротивления $a$ ) исходной и $b$ ) отожженной пленки железа. На вставке показана зависимость в интервале $T=35-2 \mathrm{~K}$ в логарифмическом масштабе.

Сопротивление как исходных, так и отожженных пленок при понижении температуры вначале увеличивается, достигает максимальной величины при температурах $T_{\max } \approx 150$ и $260 \mathrm{~K}$ соответственно и далее уменьшается, отражая доминирование характерного для металлов диффузионного механизма переноса электронов.

При $T>T_{\max }$ и в исходных, и в отожженных пленках, как можно видеть из рис. 2, температурная зависимость сопротивления не описывается активационной зависимостью, что свидетельствует о доминировании процессов перколяции по случайной сетке сопротивлений из металлических нанокристаллических островков железа и его аморфных прослоек и оксидов. Последние имеют отрицательный температурный коэффициент сопротивления, определяя температурную зависимость сопротивления в области $T>T_{\max }$. При более низких температурах начинает доминировать диффузионный механизм переноса электронов по нанокристаллитам железа. Отжиг, приводящий к улучшению структурного совершенства, однородности пленки и металлических перколяционных 


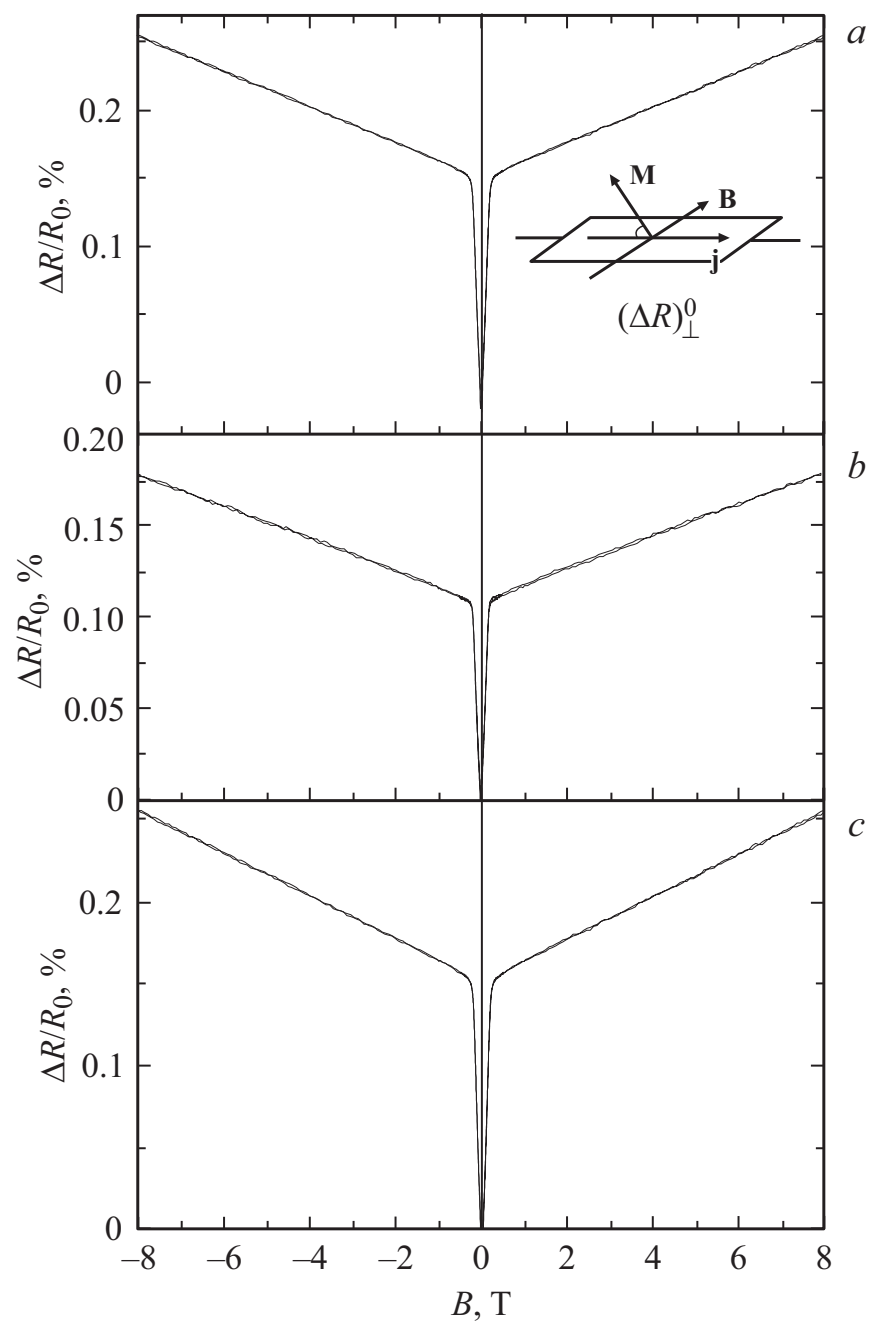

Рис. 3. Петли гистерезиса поперечного магнитосопротивления исходной пленки железа при $\varphi=0^{\circ}$, измеренные при разных температурах: $a)-300 \mathrm{~K} ; b)-100 \mathrm{~K} ; c)-2 \mathrm{~K}$.

каналов, сдвигает максимум сопротивления в высокотемпературную область (рис. 2,b) и расширяет область доминирования металлического характера переноса вплоть до $T=2 \mathrm{~K}$.

Увеличение сопротивления исходных пленок при $T \leq 35 \mathrm{~K}$ (рис. 2,a) может вызываться процессами слабой электронной локализации [9], туннелированием между металлическими кристаллитами [10], или отражать наличие магнитного фазового перехода. Проведенный анализ показал, что в интервале температур $T=35-5 \mathrm{~K}$ сопротивление исходных пленок хорошо интерполируется логарифмической зависимостью, характерной для тонких слабо разупорядоченных пленок металлов (вставка на рис. 2,a), т. е. определяется процессами слабой локализации. Отклонение от логарифмической зависимости при более низких температурах может быть связано с влиянием спин-орбитального взаимодействия на процессы электронного транспорта.
Отметим, что в пленках железа, содержащих нанометровые островки [11], наблюдаемое увеличение сопротивления при низких температурах было связано с появлением неоднородной намагниченности пленки при понижении температуры из-за замораживания направления спинов на границах островков и, как следствие, усилением спин-зависимого рассеяния.

На рис. 3-5 показаны петли гистерезиса поперечного (рис. 3, 4) и продольного (рис. 5) МС исходной пленки, измеренные при параллельной $\left(\varphi=0^{\circ}\right.$; рис. 3$)$ и перпендикулярной $\left(\varphi=90^{\circ}\right.$; рис. 4$)$ ориентациях направление магнитного поля-плоскость пленки и разных температурах.

Можно видеть, что петли гистерезиса поперечного МС при $\varphi=0^{\circ}$ и продольного эффектов (рис. 3 и 5), т. е. когда магнитное поле параллельно плоскости пленки, независимо от направления и величины магнитного поля, достаточно хорошо коррелируют по знаку, величине и виду магнитополевой зависимости. Отметим даже несколько бо́льшую величину продольного МС при

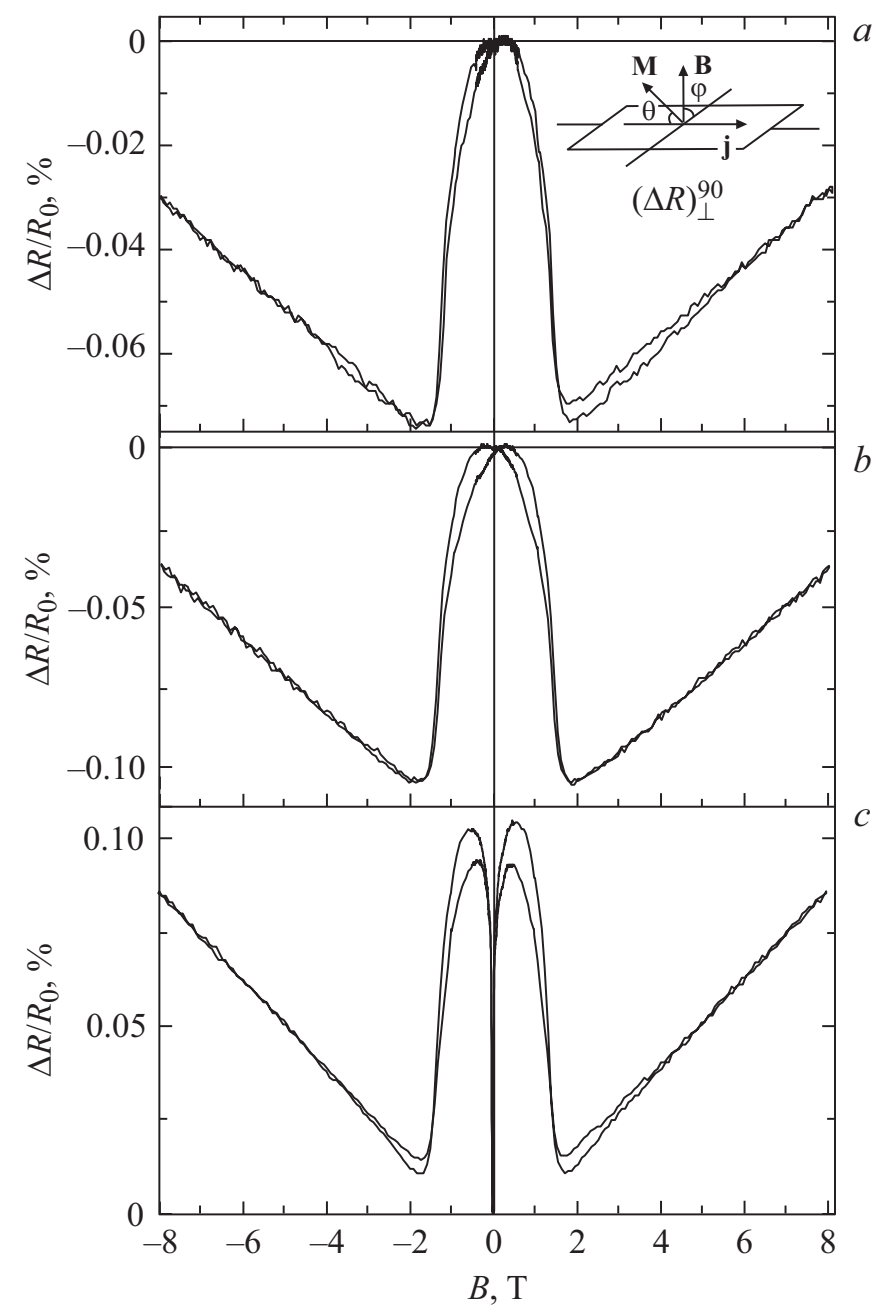

Рис. 4. Петли гистерезиса поперечного магнитосопротивления исходной пленки железа при $\varphi=90^{\circ}$, измеренные при разных температурах: $a)-300 \mathrm{~K} ; b)-100 \mathrm{~K} ; c)-2 \mathrm{~K}$. 


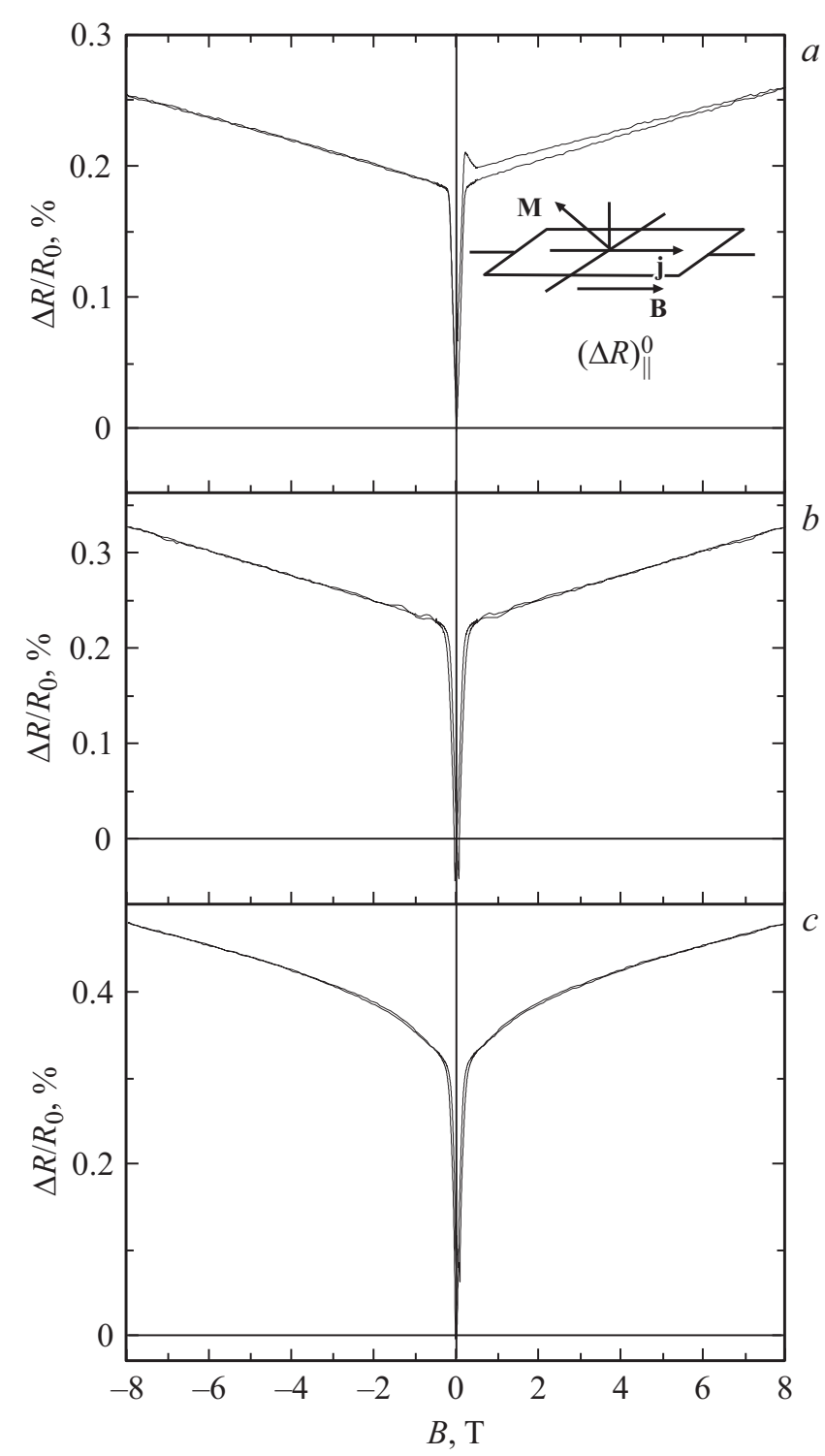

Рис. 5. Петли гистерезиса продольного магнитосопротивления, измеренные при разных температурах: a) - $300 \mathrm{~K}$; b) $-100 \mathrm{~K} ; c)-2 \mathrm{~K}$.

$T \leq 100 \mathrm{~K}$. Такая корреляция подтверждает доминирование перколяционного механизма переноса электронов вблизи комнатных температур, когда соотношение путей протекания тока перпендикулярно и параллельно магнитному полю приблизительно одинаково и МС линейно зависит от поля $[12,13]$. Изменение ориентации магнитного поля от $\varphi=0$ до $\varphi=90^{\circ}$ (рис. 3 и 4) приводит к кардинальным изменениям как знака, так и величины и вида магнитополевой зависимости поперечного МС, тогда как понижение температуры до $T=2 \mathrm{~K}$ лишь незначительно изменяет величину эффекта, за исключением $\varphi=90^{\circ}$ (рис. $4, c$ ), когда при $T=2 \mathrm{~K}$ наблюдается смена знака МС с отрицательного на положительный.

На МС исходных образцов, измеренных при разных $\varphi$ и температурах, можно выделить три характер- ные области. Так как для диффузионного механизма переноса электронов продольное ЛМС равно нулю, a поперечное очень мало и квадратично зависит от магнитного поля [3], то можно заключить, что основной вклад в измеряемый эффект могут давать следующие компоненты: анизотропия сопротивления магнитоупорядоченной среды $[2,14]$, магнонное магнитосопротивление (MМC) [5], гигантский магниторезистивный эффект $($ ГМС) $[15,16]$ и влияние магнитного поля на процессы перколяции $[12,13]$ или слабой локализации электронов в области низких температур [9].

Рассмотрим особенности трансформации МС исходных пленок в зависимости от геометрии измерения и температуры на основе феноменологической теории анизотропии сопротивления магнитоупорядоченной среды [2] и влияния магнитного поля на процессы переноса с учетом вышеотмеченных механизмов электронного транспорта и механизмов возникновения магниторезистивного эффекта. Как известно, величина сопротивления ферромагнетика больше, когда направление тока параллельно намагниченности. В этом случае внешнее магнитное поле приводит к увеличению сопротивления (положительное $\mathrm{MC}$, ПМС), а при взаимно перпендикулярной ориентации - к его уменьшению (отрицательное МС, ОМС). При достижении намагниченности насыщения (область сильных полей) дальнейшее увеличение поля может приводить как к увеличению, так и уменьшению сопротивления магнитоупорядоченной среды, т.е. к ПМС или ОМС в зависимости от доминирующего механизма проводимости.

На рис. $6, a-c$ приведены те же зависимости в области слабых магнитных полей при температуре $T=100 \mathrm{~K}$, показывающие особенности смены знака МC.

В геометрии измерения $\varphi=0^{\circ}$ как поперечное, так и продольное $\mathrm{MC}$ изменяют знак с отрицательного на положительный (рис. $6, a$ и $c$ ), а при $\varphi=90^{\circ}$ (рис. 6, $b$ ) очень малое поперечное ПМС наблюдается только при уменьшении магнитного поля от максимальной величины до нуля при $B \approx 0,3 \mathrm{~T}$. Направление изменения поля на рис. 6 показано стрелками. Такие зависимости, когда в намагниченном состоянии сопротивление образца больше, не характерны для обычного ГМС $[15,16]$, но характерны для инверсного ГМС, наблюдающегося в магнитно-неоднородной среде [17], т.е. в среде, в которой одна из магнитных фаз имеет проводимость электронов с направлением спина вниз больше, чем проводимость со спином вверх. Это позволяет определить коэрцитивную силу, а независимость АМС от поля в поле, большем поля насыщения намагниченности определить его величину. Величины коэрцитивной силы и поля насыщения намагниченности при $T=300 \mathrm{~K}$, полученные из измерений петель гистерезиса намагниченности $[7,8]$ и $\mathrm{MC}$ исходных и отожженных пленок при разных углах $\varphi$ приведены в таблице и достаточно хорошо согласуются.

Понижение температуры до $T=2 \mathrm{~K}$ приводит к доминированию в исходных пленках процессов слабой 

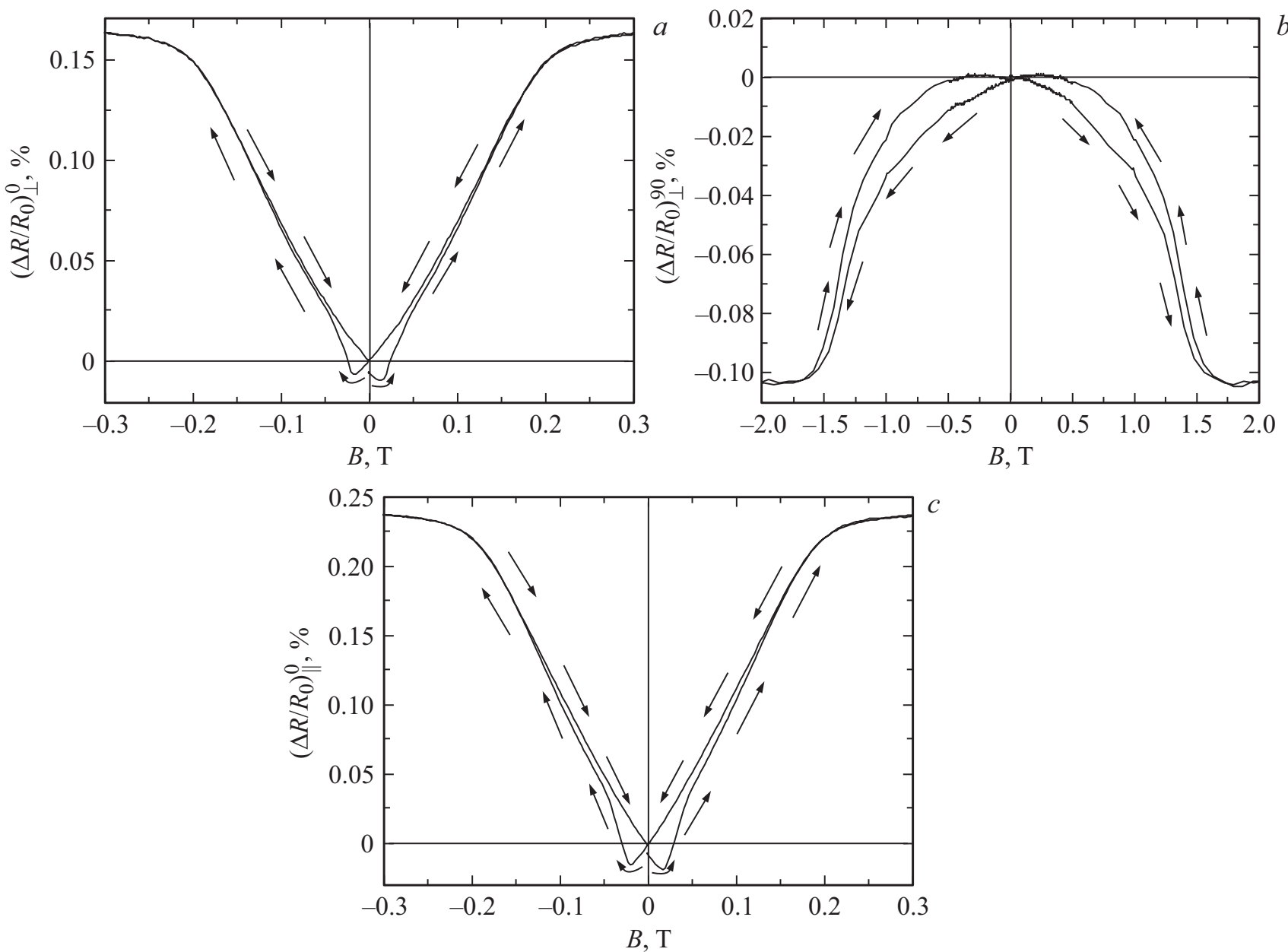

Рис. 6. Петля гистерезиса поперечного $-a) \varphi=0$ и $b) \varphi=90^{\circ}-$ и $c$ ) продольного магнитосопротивления, при $T=100 \mathrm{~K}$ исходной пленки железа в слабом магнитном поле.

локализации и/или электрон-электронного взаимодействия [9], что подтверждает логарифмическая зависимость сопротивления от температуры при $T<35 \mathrm{~K}$. При этом в слабом поле гистерезистных явлений

Значения коэрцитивной силы $B_{c}$ и поля насыщения намагниченности $B_{s}$ при $T=300 \mathrm{~K}$, полученные из измерений петель гистерезиса намагниченности и магниторезистивного эффекта в исходных и отожженных пленках при разных углах между плоскостью пленки и направлением магнитного поля

\begin{tabular}{c|c|c|c|c|c}
\hline & Образец & \multicolumn{2}{|c|}{ Исходный } & \multicolumn{2}{c}{ Отожженный } \\
\hline Угол $\varphi, \operatorname{deg}$ & Характеристика & $B_{c}, \mathrm{~T}$ & $B_{s}, \mathrm{~T}$ & $B_{c}, \mathrm{~T}$ & $B_{s}, \mathrm{~T}$ \\
\hline \multirow{2}{*}{0} & $\mathrm{M}(0)$ & 15 & 0.2 & 7 & 0.1 \\
\cline { 2 - 6 } & $(\Delta R)_{\perp}^{0}$ & 16 & 0.2 & 13 & 1 \\
\hline \multirow{2}{*}{90} & $\mathrm{M}(90)$ & 5 & 1.25 & 6 & 2 \\
\cline { 2 - 6 } & $(\Delta R)_{\perp}^{90}$ & - & 1.7 & - & 2 \\
\hline \multirow{2}{*}{0} & $\mathrm{M}(0)$ & 15 & 0.2 & 7 & 0.1 \\
\cline { 2 - 6 } & $(\Delta R)_{\|}^{0}$ & 19 & 0.2 & 12 & 1
\end{tabular}

и смены знака MC, характерного для температур выше $T>100 \mathrm{~K}$, не наблюдается. Когда магнитное поле лежит в плоскости пленки, как поперечное, так и продольное МC в слабом и сильном поле имеют положительный знак и близкие к линейной зависимости от магнитного поля, обусловленные доминированием положительной компоненты AMC в слабом поле и влиянием поля на процессы перколяции в сильном.

Обсудим причины изменения знака поперечного МС в исходных пленках при переориентации направления магнитного поля относительно плоскости пленки от $\varphi=0$ до $\varphi=90^{\circ}$. Как видно из сравнения рис. 3 и 5 с рис. 4, независимо от измеряемого эффекта (поперечный или продольный), изменение $\varphi$ приводит к смене знака МС с положительного на отрицательный при $T>10 \mathrm{~K}$. В режиме слабой локализации МС только положительно и показывает резкое увеличение или уменьшение практически до нуля при $B \approx 2$ Т и линейный рост в более сильном поле. Так как АМС имеет отрицательный знак при взаимно перпендикулярном направлении протекающего тока и намагниченности образца, то такое изменение знака МС свидетельствует 


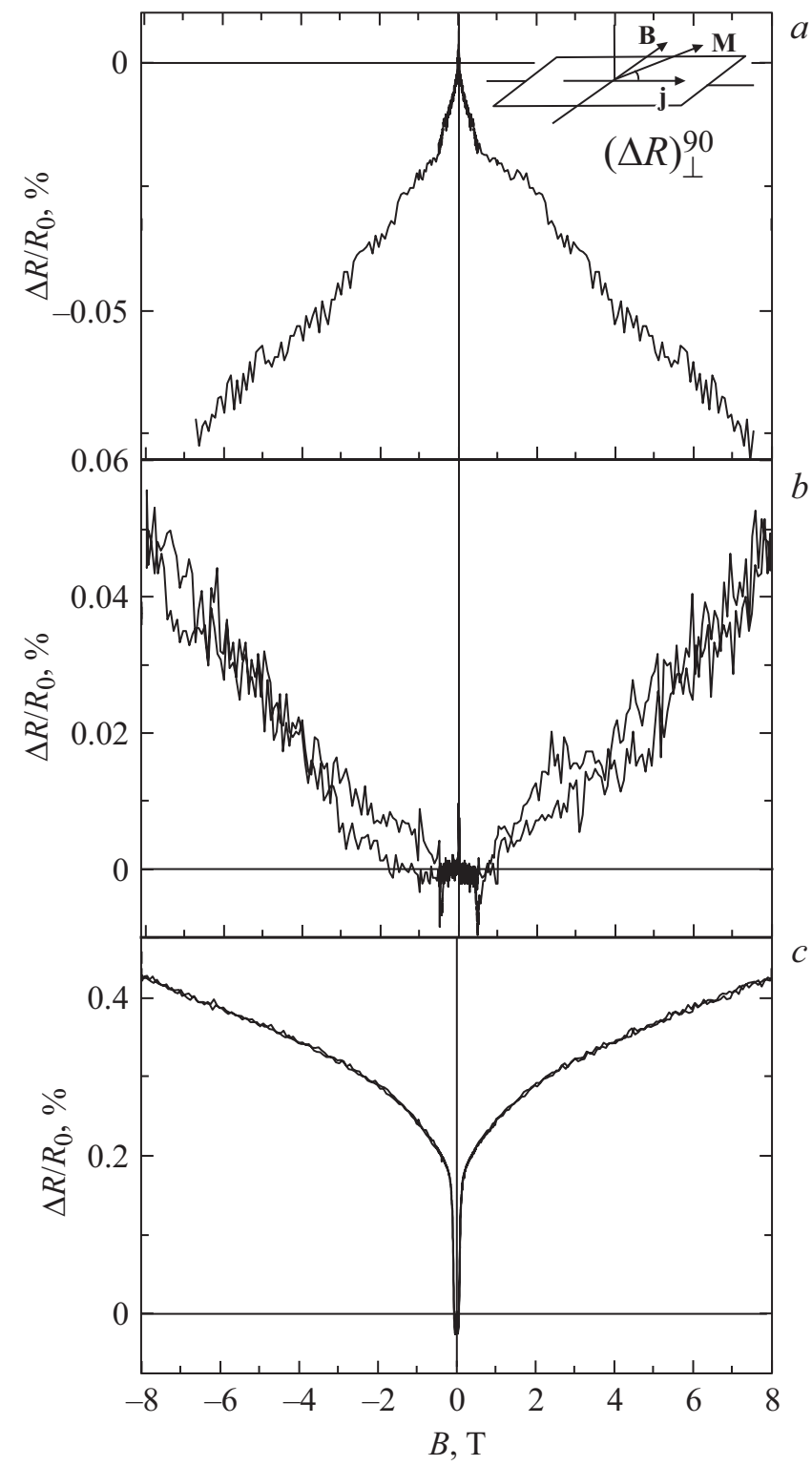

Рис. 7. Петли гистерезиса поперечного магнитосопротивления отожженной пленки железа при $\varphi=0^{\circ}$, измеренные при разных температурах: $a)-300 \mathrm{~K} ; b)-100 \mathrm{~K} ; c)-2 \mathrm{~K}$.

о наличии перпендикулярной магнитной анизотропии в исходных пленках при измерении поперечного МС и $\varphi=90^{\circ}$. Действительно, в этом случае увеличение перпендикулярного плоскости пленки магнитного поля приводит к окончательному повороту намагниченности до направления перпендикулярного протекающему току, т. е. доминированию отрицательной компоненты АМС. По данным мессбауэровской спектроскопии, намагниченность в исходных пленках ориентирована под углом около $75^{\circ}$ к плоскости пленки.

Как отмечалось ранее, отжиг образцов приводит не только к смене преобладающего механизма проводимости в разных температурных диапазонах, но и доминированию намагниченности в плоскости пленки и, как следствие, к кардинальным изменениям МС. Эти изменения наиболее отчетливо проявляются при понижении температуры. На рис. 7-9 приведены петли гистерезиса поперечного (рис. 7,8) и продольного (рис. 9) MC отожженной пленки, измеренные при параллельной (рис. 7,9) и перпендикулярной (рис. 8) ориентациях направления магнитного поля - плоскость пленки.

В первую очередь надо отметить изменение при отжиге знака поперечного при $\varphi=0^{\circ}$ и продольного МС с положительного на отрицательный при $T=300 \mathrm{~K}$ (рис. 3 и 5; 7 и 9). Понижение температуры до $T=100 \mathrm{~K}$ также приводит к кардинальным изменениям знака и вида магнитополевой зависимости поперечного при

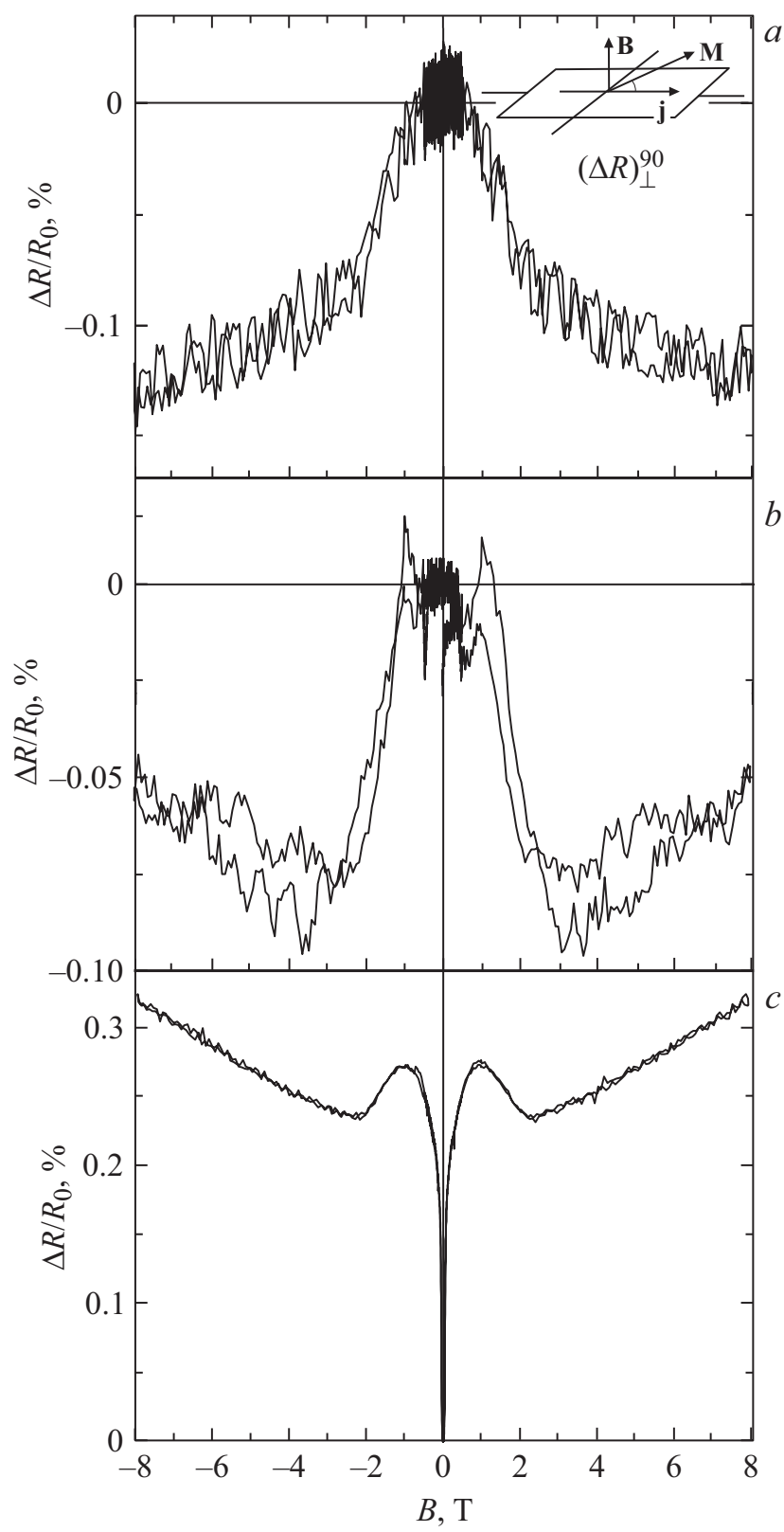

Рис. 8. Петли гистерезиса поперечного магнитосопротивления отожженной пленки железа при $\varphi=90^{\circ}$, измеренные при разных температурах: $a)-300 \mathrm{~K} ; b)-100 \mathrm{~K} ; c)-2 \mathrm{~K}$. 


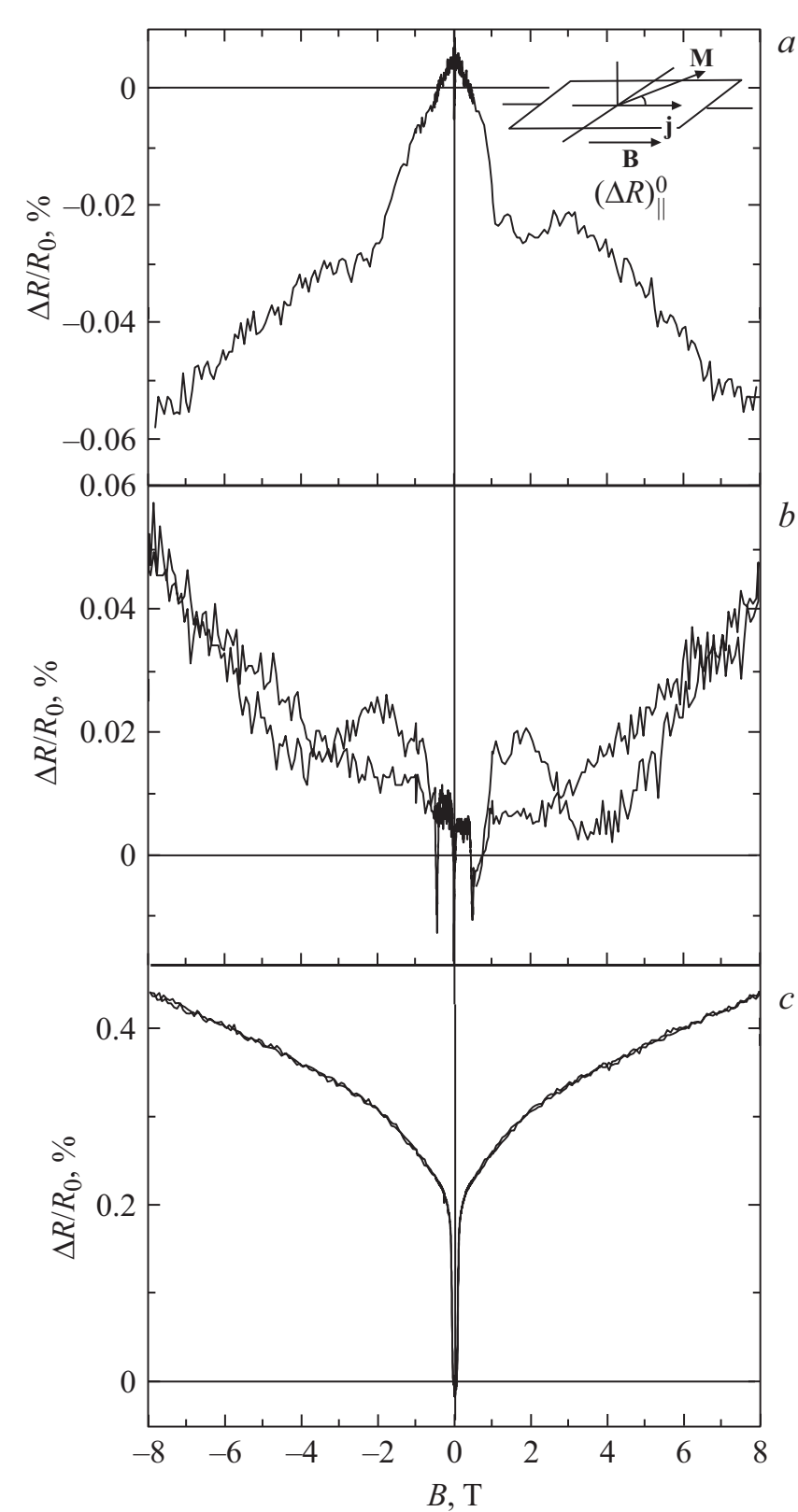

Рис. 9. Петли гистерезиса продольного магнитосопротивления отожженной пленки железа, измеренные при разных температурах: $a)-300 \mathrm{~K} ; b)-100 \mathrm{~K} ; c)-2 \mathrm{~K}$.

$\varphi=0^{\circ}$ и продольного эффектов, а именно к смене знака эффекта с отрицательного на положительный. При $\varphi=90^{\circ}$ знак эффекта остается отрицательным, однако в сильном поле наклон магнитополевой зависимости сменяется с отрицательного на положительный (рис. 8, a и $b$ ), отражая доминирование положительной компоненты перколяционного МС в сильном поле.

Линейная зависимость ОМС магнитоупорядоченных сред в области сильных магнитных полей обуславливается доминированием магнонного рассеяния, которое теоретически предсказано и экспериментально подтверждено для $3 d$-металлов [5]. Как и следовало ожидать, уменьшение числа магнонов при понижении температуры приводит к доминированию влияния поля на перколяционные процессы и, как следствие, к близким величинам положительного поперечного и продольного МС (рис. 7 и 9, b), а также доминированию положительной компоненты МС при отрицательном знаке поперечного МС при $\varphi=90^{\circ}$ в сильном магнитном поле $B>2 \mathrm{~T}$ (рис. $8, b)$. Отметим, что оцененная по результатам измерения линейного не насыщающегося продольного отрицательного ММС пленок железа в поле до $40 \mathrm{~T}$, температура вымораживания магнонов в них составляет около $160 \mathrm{~K}$ [5].

Показатель степени магнитополевой зависимости МС $\left(\Delta R \sim B^{\alpha}\right)$ при $T=100 \mathrm{~K}$ несколько больше, чем в исходных образцах $(\alpha=1$, рис. 3 и $5, b)$, но меньше характерной для положительного ЛМС ( $\alpha=2)$ [3], что отражает лучшее структурное совершенство отожженных пленок и меньшее влияние процессов перколяции на МC. При этой температуре МС достаточно хорошо экстраполируются степенной зависимостью с $\alpha \approx 1.5$.

Доминирование чисто металлического характера переноса электронов в отожженных пленках при $T=2 \mathrm{~K}$ позволяет выделить при этой температуре две компоненты MC: AMC в области слабых магнитных полей до поля насыщения намагниченности и положительную компоненту с близкой к линейной зависимостью в сильном поле независимо от геометрии измерения. Как и в исходных образцах, в сильном поле поперечный и продольный эффекты незначительно отличаются по величине и имеют близкую к линейной зависимость от поля (рис. 7-9 $(c)$ ), что свидетельствует о доминировании перколяционного механизма переноса электронов при низких температурах.

Отметим появление шумов в виде резких пиков МС в отожженных пленках в магнитном поле до $B \approx 0.5 \mathrm{~T}$ при $T<100 \mathrm{~K}$, обусловленных движением доменных стенок [4-19]. Эти пики наиболее отчетливо проявляются при взаимно перпендикулярной ориентации поле - плоскость пленки уже при комнатной температуре (рис. $8, a$ ) и не наблюдаются при $T=2 \mathrm{~K}$ независимо от угла (рис. 8). На рис. 10, $a-c$ показаны эти же зависимости при $T=100 \mathrm{~K}$ в области магнитных полей до $B=2$ Т. Стрелками показано направление изменения магнитного поля. Можно видеть, что в отличие от исходных пленок, сопротивление отожженных пленок в намагниченном состоянии меньше (см. рис. 6 и 10), т.е. в результате отжига улучшилась не только структура, но и магнитная однородность пленки, а наличие резких пиков МС свидетельствует о многодоменной структуре кристаллитов.

Петли гистерезиса поперечного при $\varphi=0^{\circ}$ и продольного МС в области слабых магнитных полей показаны на вставках рис. 10, $a$ и $c$. Можно видеть, что независимо от измерения поперечного или продольного МС, когда магнитное поле в плоскости пленки, пики МС при $B \approx 0.5 \mathrm{~T}$ имеют отрицательный знак и наблюдаются при уменьшении магнитного поля от максимальной 

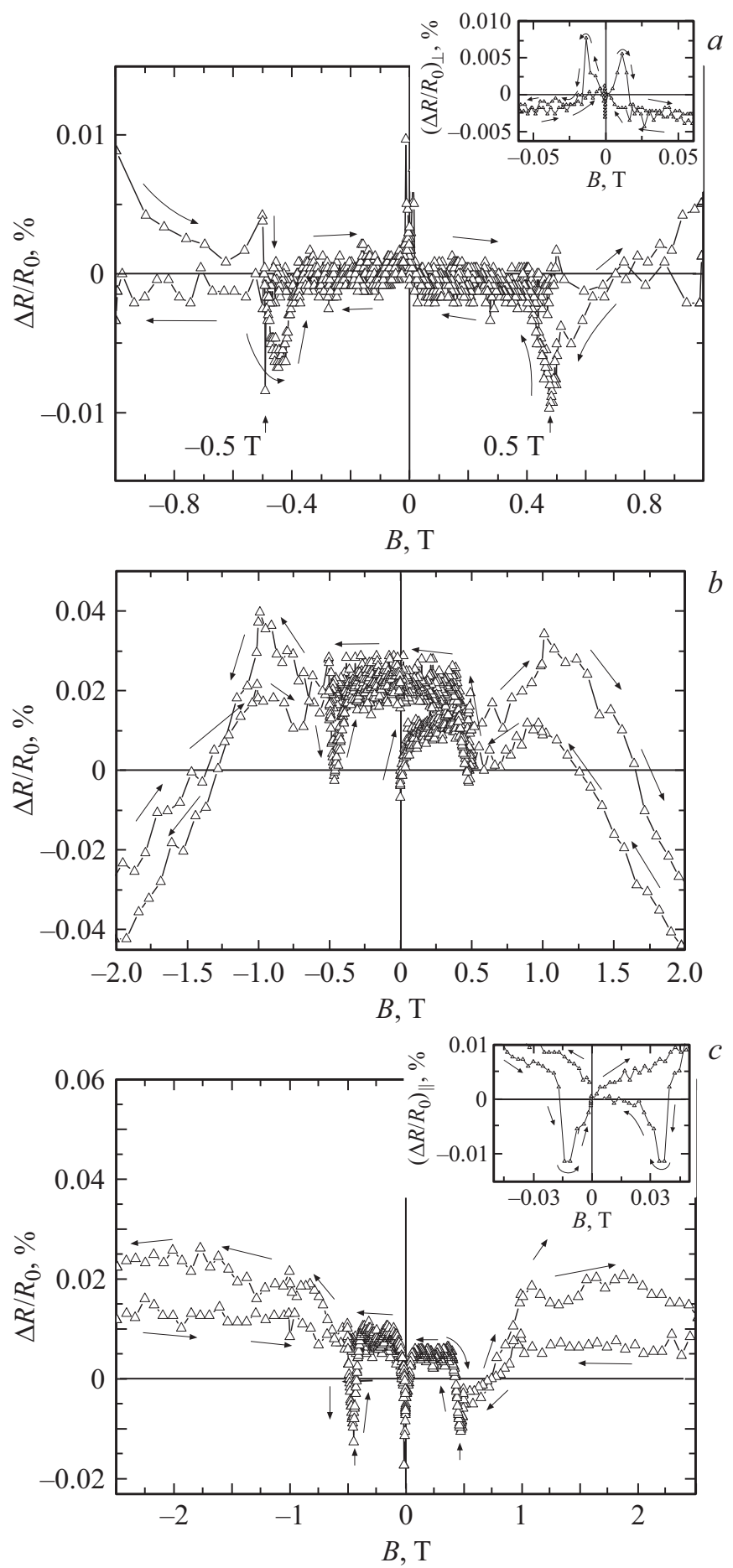

Рис. 10. Петля гистерезиса поперечного магнитосопротивления при $T=100 \mathrm{~K}$ отожженной пленки железа в магнитном поле до $B=2.5$ Т при $a) \varphi=0^{\circ}$; $\left.b\right) \varphi=90^{\circ}$; и $c$ ) продольного. На вставках рис. 10, $a$ и $c$ показаны петли в области слабых полей.

величины до нуля, т.е. при уменьшении намагниченности. Положение этих пиков хорошо коррелирует с резким (практически без изменения поля) скачком намагниченности в случае измерения петли только при $\varphi=90^{\circ}$, которое может быть обусловлено изменением направления намагниченности домен одной из фаз на противоположное. Надо отметить, что пики МС при $B \approx 0.5$ Т наблюдаются и при перемагничивании образца в противоположном направлении, однако амплитуда их много меньше.

Резкие пики ОМС при размагничивании наблюдаются и в слабом поле $(B \approx 14-35 \mathrm{mT}$, вставка на рис. $10, c)$ при измерении продольного МС. При измерении поперечного МС при $\varphi=0^{\circ}$, т.е. когда поле, как и в продольном эффекте в плоскости пленки, эти пики наблюдаются в несколько меньшем поле $(B \approx 12 \mathrm{mT}$, вставка на рис. $10, a)$, имеют положительный знак и характерны только для перемагничивания образца в противоположном направлении. В поперечном МС в геометрии $\varphi=90^{\circ}$ пики МС выделить не удается из-за наличия сильных шумов.

Резкие пики МC, наблюдаемые независимо от геометрии измерения в магнитном поле $B \approx 0.5 \mathrm{~T}$, соответствуют началу необратимой перестройки доменной структуры (движению доменных стенок) одной магнитной фазы, а в слабом поле - другой (или движению доменных стенок другого типа). В магнитных пленках толщиной $d<20-30 \mathrm{~nm}$ доминируют стенки Нееля, а большей стенки Блоха [20]. В пленках промежуточной толщины до $d \approx 120 \mathrm{~nm}$ возможно существование обоих типов стенок, так называемые стенки с перевязками или стенки более сложного типа. Можно предположить, что разный характер изменения направления намагниченности в стенках блоховского и неелевского типов при разных геометриях измерения МС приводит к противоположным по знаку изменения сопротивления, т.е. к пикам положительного и отрицательного МС. Однако для окончательного ответа о влиянии типа доменных стенок и их перестройки в магнитном поле на МС требуются дополнительные исследования.

\section{5. Заключение}

В исходных и отожженных нанокристаллических пленках железа с разным видом магнитной анизотропии, полученных методом ионно-стимулированного осаждения на кремниевых подложках, обнаружена зависимость знака, величины и вида магнитополевой зависимости магниторезистивного эффекта в области магнитных полей до насыщения намагниченности от вида магнитной анизотропии, угла между направлением магнитного поля и плоскостью пленки, а также температуры измерения, обусловленная наличием спонтанной намагниченности пленки и изменением механизма переноса электронов при понижении температуры и отжиге от перколяционного в области комнатных температур до режима слабой локализации при низких температурах через доминирование металлического переноса при промежуточных температурах. 
Установлено, что в исходных пленках с перпендикулярной магнитной анизотропией в температурном интервале доминирования перколяционной проводимости до поля насыщения намагниченности наблюдается смена знака поперечного и продольного МС при $\varphi=0^{\circ}$ с положительного на отрицательный при изменении направления магнитного поля от параллельного плоскости пленки до перпендикулярного, из-за доминирования анизотропной компоненты отрицательного МС, когда направление тока перпендикулярно намагниченности. В сильном поле уменьшение величины отрицательного МC вызывается доминированием положительной компоненты перколяционного МС. В слабом поле в поперечном и продольном эффектах при $\varphi=0^{\circ}$ обнаружен инверсный гигантский магниторезистивный эффект, обусловленный магнитной неоднородностью пленок.

В отожженных пленках с анизотропией в плоскости при $T=300 \mathrm{~K}$, независимо от геометрии измерения, в области слабых магнитных полей доминирует компонента анизотропного МС, а в области сильных - линейное не насыщающееся отрицательное магнонное МC. Обнаружены смена знака поперечного и продольного эффектов с отрицательного на положительный при $\varphi=0^{\circ}$ и понижении температуры из-за вымораживания магнонов, а также при $\varphi=0^{\circ}$ и $T=100 \mathrm{~K}$ линейное уменьшение отрицательного МС в сильном поле из-за доминирования положительной компоненты лоренцевского МС и резкие пики увеличения и уменьшения $\mathrm{MC}$, обусловленные движением доменных стенок как при перемагничивании, так и размагничивании пленок.

Показано, что характеристические поля изменения знака и вида магнитополевой зависимости МС при разных геометриях измерения достаточно хорошо согласуются с характеристическими полями петель гистерезиса намагниченности, а именно: коэрцитивной силой и полем насыщения намагниченности, измеренными при $\varphi=0$ и $\varphi=90^{\circ}$.

\section{Благодарности}

Авторы выражают благодарность Д.А. Бизяеву за исследование доменной структуры пленок железа методом магнитно-силовой сканирующей микроскопии.

\section{Финансирование работы}

Синтез образцов и статические магнитные измерения проводилось в рамках Государственного задания КФТИ ФИЦ КазНЦ РАН № AАAА-A18-118041760011-2.

\section{Конфликт интересов}

Авторы заявляют, что у них нет конфликта интересов.

\section{Список литературы}

[1] I. Čutić, J. Fabian, S. Das Sarma. Rev. Mod. Phys. 76, 2, 323 (2004).

[2] I.A. Campbel, A. Fert. Transport Properties of Ferromagnets. In: Ferromagnetic Materials. Amsterdam, N.Y., Oxford (1982). P. 747-805.

[3] A.G. Beer. Galvanomagnetic effects in semiconductors. In: Solid State Physics, Suppl. 4 / Eds F. Zeitz, D. Turnbull. N.Y.-London (1963). 418 p.

[4] U. Ruediger, J. Yu, S. Zhang, A.D. Kent, S.S.P. Parkin. Phys. Rev. Lett. 80, 25, 5639 (1998).

[5] B. Raquet, M. Viret, E. Sondergard, O. Cespedes, R. Mamy. Phys. Rev. B 66, 2, 024433 (2002).

[6] X. Battle, A. Labarta. J. Phys. D 35, 6, R15 (2002).

[7] N.M. Lyadov, V.V. Bazarov, F.G. Vagizov, I.R. Vakhitov, E.N. Dulov, R.N. Kashapov, A.I. Noskov, R.I. Khaibullin, V.A. Shustov, I.A. Faizrakhmanov. Appl. Surf. Sci. 378, 114 (2016).

[8] N.M. Lyadov, F.G. Vagizov, I.R. Vakhitov, A.I. Gumarov, Sh.Z. Ibragimov, D.M. Kuzina, I.A. Faizrakhmanov, R.I. Khaibullin, V.A. Shustov. Vacuum 168, 108860 (2019).

[9] G. Bergman. Phys. Rev. B 107, 1, 1 (1984).

[10] B. Abeles, P. Sheng, M. Coutts, Y. Arie. Adv. Phys. 24, 407 (1975).

[11] Z. Sefrioui, J.L. Menéndez, E. Navarro, A. Cebollada, F. Briones, P. Crespo, A. Hernando. Phys. Rev. B 64, 22, 224431 (2001).

[12] А.Я. Шик, А.Н. Дахно, О.В. Емельяненко, Т.С. Лагунова. ФТП 14, 6, 1110 (1980).

[13] А.Я. Шик. ФТП 9, 5, 872 (1975).

[14] R.R. Birss. Proceed. Roy. Soc. 75, 1, 8 (1960).

[15] M.N. Baibich, J.M. Broto, A. Fert, F. Nguyen Van Dau, F. Petroff, P. Etienne, G. Creuzet, A. Friederich, J. Chazelas. Phys. Rev. Lett. 61, 21, 2472 (1988).

[16] A.E. Berkowitz, J.R. Mitchell, M.J. Carey, A.P. Young, S. Zhang, F.E. Spada, F.T. Parker, A. Hutten, G. Thomas. Phys. Rev. Lett. 68, 25, 3745 (1992).

[17] X. Li, H. Li, M. Jamali, J.P. Wang. AIP Advances 7, 12, 125303 (2017).

[18] D. Ravelosona, A. Cebollada, F. Briones. Phys. Rev. B 59, 4322 (1999).

[19] J.F. Gregg, W. Allen, K. Ounadjela, M. Viret, M. Hehn, S.M. Thompson, J.M.D. Coey. Phys. Rev. Lett. 77, 8, 1580 (1996).

[20] В.Г. Казаков. Тонкие магнитные пленки. Сорос. образоват. журн. 1, 107 (1997).

Редактор Е.В. Толстякова 